\title{
BMJ Open Impact of workplace incivility against new nurses on job burn-out: a cross- sectional study in China
}

\author{
Yu Shi, ${ }^{1}$ Hui Guo, ${ }^{2}$ Shue Zhang, ${ }^{3}$ Fengzhe Xie, ${ }^{1}$ Jinghui Wang, ${ }^{1}$ Zhinan Sun, ${ }^{4}$ \\ Xinpeng Dong, ${ }^{5}$ Tao Sun, ${ }^{1}$ Lihua Fan ${ }^{1}$
}

To cite: Shi Y, Guo H, Zhang S, et al. Impact of workplace incivility against new nurses on job burn-out: a cross-sectional study in China. BMJ Open 2018;8:e020461. doi:10.1136/ bmjopen-2017-020461

- Prepublication history for this paper is available online. To view these files, please visit the journal online (http://dx.doi. org/10.1136/bmjopen-2017020461).

YS, HG and SZ contributed equally.

Received 7 November 2017 Revised 6 February 2018 Accepted 20 February 2018

\begin{abstract}
This study had three objectives: (1) to investigate the impact of workplace incivility on job burnout of new nursing staff, (2) to verify the partial mediating role of anxiety in the relationship between workplace incivility and job burn-out, (3) to examine the resilience moderating the relations between workplace incivility and job burn-out.

Design A cross-sectional online survey was conducted in May 2016 in China.

Setting The survey was conducted in 54 cities across 29 provinces of China.

Participants A total of 903 participants were invited. Ultimately, 696 new nurses ( $<3$ service years) completed valid questionnaires. The effective response rate was $77.1 \%$. Entry criteria: voluntary participation, having less than three service years and being a registered nurse. Exclusion criteria: being an irregular nurse, having more than three service years and refusing to participate in this work.
\end{abstract}

Outcome measures An anonymous questionnaire was distributed among new nurses. The relationships and mechanism among the variables were explored using descriptive statistical analysis, Pearson's correlation coefficient and multiple linear regression analysis.

Results The findings showed that workplace incivility was positively correlated with anxiety $(r=0.371, p<0.01)$ and job burn-out $(r=0.238, p<0.01)$ of new nurses. The positive relation between anxiety $(\beta=0.364, p<0.01)$ and job burnout $(\beta=0.240, p<0.01)$ was also significant. Moreover, anxiety partially mediated $(z=7.807, p<0.01)$ and resilience moderated $(\beta=-0.564, p<0.01)$ the association between workplace incivility and job burn-out.

Conclusion Experience of workplace incivility by new nurses would likely generate anxiety in the victims. Further, the increased anxiety state could elevate their level of job burn-out. New nurses with high levels of resilience could buffer the negative influence of workplace incivility by using a positive coping style.

\section{INTRODUCTION}

\section{Background/literature review}

Workplace incivility was regarded as a negative behaviour by organisation members which was clearly proposed by Katz in $1964{ }^{1}$ However, this kind of behaviour and its negative consequences did not attract attention from management researcher at that time. ${ }^{2}$
Strengths and limitations of this study

- This is the first study investigating the relationship of workplace incivility with anxiety, resilience and job burn-out of new nurses.

- The finding that anxiety partially mediated the relationship between workplace incivility and job burnout is first reported among new nurses.

- This research has innovatively examined the resilience moderating the relations between workplace incivility and job burn-out.

- The method to self-reports of new nurses by an online survey may have led to response bias, and causation cannot be established due to the cross-sectional study design.

The regional data source ratio would be unbalanced.

After nearly 30 years of exploration practice, Andersson and Pearson formally defined workplace incivility in 1999 as follows: 'Workplace incivility is low-intensity deviant behavior with ambiguous intent to harm the target, in violation of workplace norms for mutual respect. Uncivil behaviors are characteristically rude and discourteous, displaying a lack of regard for others. ${ }^{3}$ In 2002, a new concept of workplace incivility was put forward by Western researchers. Lauer considered that uncivil behaviour harmed employees' self-esteem in the organisation, causing harm to employees by disrespectful behaviour, ${ }^{4}$ but it is completely distinct from physical aggression and violence. Workplace incivility has characteristics similar to the subtle spiral infiltration model. It would be accumulated at a low level for a long time, and the final outcome rises to a high level of harm to employees. The harm is sustained over a long period, and, therefore, the physical and mental damage to the victim is difficult to recover in the short term. ${ }^{5}$ According to previous reports, the influence of workplace incivility on mental health of employees mainly included anxiety, cognitive dissonance, excessive worry, stress and mental depression and so on. ${ }^{6}$ The impact on physical 
health includes migraine headaches, stomach ulcers, high blood pressure and so on. ${ }^{6}$ Typically, uncivil behaviours are unobserved and add up over time. Moreover, if a hospital organisation cannot respond properly, these uncivil behaviours may lead to adverse organisational and individual effects. ${ }^{3}$ Over time, the organisational conflict caused by uncivil behaviour would emerge, ${ }^{7}$ and serious consequences will gradually appear in large numbers in the group, such as the absenteeism, ${ }^{8}$ less organisational citizenship behaviour, ${ }^{9}$ productivity slowdown, ${ }^{10}$ lower job satisfaction, ${ }^{11}$ lower organisational loyalty ${ }^{12}$ and even heightened turnover intentions. ${ }^{13}$

In recent years, residents' expectations regarding medical service continue to rise. ${ }^{14}$ Due to the large population in China, an appropriate number of nurses is needed to deliver healthcare services to meet the health needs. ${ }^{15}$ Therefore, the sustainable recruitment of nurses and acceleration of their career development is crucial for the nursing field. Improving the skills of nursing staff relies on healthy career development, which is a key task for China's healthcare service system. Further, the Chinese health system faces problems such as weak medical service capacity in primary hospitals, health human resources of insufficient quality, rising healthcare costs, fragmented medical services and so on. ${ }^{16}$ Novice nurses (working service less than 3 years) as the new force of the nursing team is the basis for the prosperity and development of the nursing team. These new nurses have the characteristics of young age, lack of work experience and weak psychological coping ability. Yet, there is a high degree of job stress of new graduates in the Chinese healthcare climate. Therefore, new nurses often lack the skills to cope with problems in the new working conditions. The active adaptation, good job involvement, and physical and mental health of the new nurses are regarded as motivating forces to encourage them and are greatly beneficial to their career success in the long term. An active, enthusiastic and positive attitude towards nursing work at the beginning of one's career is necessary for new nurses. ${ }^{17}$ However, new nurses early in their career are likely to encounter variously offensive behaviours, which violate the principle of equality and respect among organisation members and are highly hurtful with low intensity. ${ }^{5}$ These adverse behaviours under long-term generation must lead to irreversible damage to the new nurses' physical and mental health. Meanwhile, they must also severely hinder the construction of the medical and nursing team. Unfortunately, there are no related experts and researchers focused on the phenomenon of workplace incivility against new nurses in China.

Some scholars pointed out that workplace incivility was associated with job burn-out among restaurant service employees. ${ }^{18}$ Job burn-out is an individual reaction to emotional and interpersonal stress and is related to work pressure and occupational stress. ${ }^{19}$ Previous study showed a high incidence in the nursing group. ${ }^{20}$ Worse still, job burn-out can result in a series of adverse outcomes for nursing staff and hospital organisations, such as disappearance of sense of organisation belonging, ${ }^{21}$ decline of nursing group cohesion, ${ }^{22}$ poor nursing work efficiency and lower job performance. It may even lead to the loss of nursing talents. ${ }^{23}$ The reasons for job burn-out have been analysed and mainly include excess workload, ${ }^{24}$ lack of support and resources, ${ }^{25}$ impeded information and reduced sense of control, ${ }^{24}$ organisational injustice, ${ }^{26}$ interpersonal roles conflict, ${ }^{27}$ and interpersonal emotional stress at work. ${ }^{28}$ In addition, some researchers have conducted many studies to explore the relationship between incivility and job burn-out in the nursing workplace. ${ }^{20}$ However, previous studies exhibited a complete lack of concern for new nurses. Further, during recent years, although researchers have successfully explained the role mechanism of job burn-out under the resource perspective, there are no researchers illustrating the mechanism of the relationship between workplace incivility and job burn-out.

Additionally, the awareness of workplace incivility has been greatly enhanced recently, especially of the effects of uncivilised workplace behaviour on the psychological health of employees. ${ }^{29}$ A new study also sheds light on the workplace incivility experienced by Australian adult workers. The finding indicates that workplace incivility is positively linked with anxiety. ${ }^{30}$ Anxiety is seen as an adaptive motivational behaviour that helps individuals cope with threatening situations. ${ }^{31}$ From the evidence of another study, anxiety refers to an unpleasant emotional state that mainly includes such feelings as apprehension, tension and worry. ${ }^{32}$ Anxiety is considered to be caused by stimuli from the external environment. When people experience workplace incivility, they may feel anxious. ${ }^{32}$ For example, their work performances are not being respected, or they receive other people's unreasonable malicious evaluations. Anxious employees are more apt to experience emotional exhaustion, body fatigue, reduced work involvement and lower job satisfaction with the continuous depletion of psychological resources. In other words, anxiety could increase the risk of employees' job burn-out. Resilience is the ability to bounce back or cope successfully despite adverse circumstances. ${ }^{33}$ It is used to describe when a person recovers easily and quickly from setbacks that occur during his or her life. It is worth mentioning that the core of resilience is strength, and people who are described as resilient are said to be able to persist in overcoming challenging obstacles. Therefore, resilience is nurses' ability to successfully adjust and recover in adversity, which plays an important role when employees experience workplace incivility. ${ }^{33}$ One study indicated that resilience was a moderator between work stress and job burn-out. ${ }^{34}$ Therefore, the following hypotheses are proposed in this study regarding the group of new nurses.

\section{Hypothesis 1}

Workplace incivility has a positive prediction function to generate anxiety among new nurses. 
H4

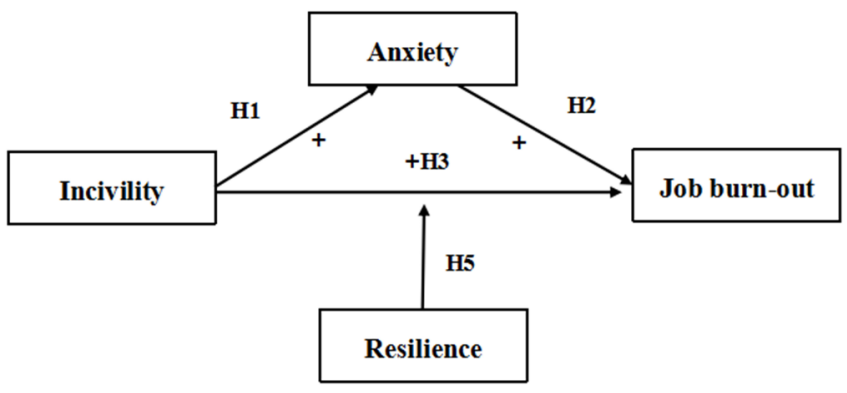

Figure 1 The conceptual framework of study.

\section{Hypothesis 2}

Anxiety positively predicts job burn-out among new nurses.

\section{Hypothesis 3}

Workplace incivility has a positive prediction function to generate job burn-out among new nurses.

\section{Hypothesis 4}

Anxiety mediates the relationship between workplace incivility and job burn-out.

\section{Hypothesis 5}

Resilience moderates the relationship between workplace incivility and job burn-out as shown in figure 1 .

\section{METHOD AND ANALYSIS \\ Sample/participants}

New nurses who had been working less than 3 years were recruited as the sample of current research from a hospital in China in 2016. A total of 903 questionnaires (including the Workplace Incivility Scale, Anxiety Scale, Resilience Scale and Job Burn-out Scale) were distributed among new nurses; A total of 696 questionnaires were returned. The effective response rate was $77.1 \%$.

\section{Data collection}

An anonymous online questionnaire was completed by nurses with less than 3 years of working throughout the country in May of 2016 in China. In this study, the method of snowball sampling was used to collect the sample data. In the network survey, original deliverers used in this survey are alumni who maintain friendly contact with us, who work in nursing positions in various hospitals. Before a formal online survey begins, we have provided comprehensive survey training to these initial contacts. Then encourage them to invite their colleagues or classmates to fill out the questionnaire. This survey is to use their network of relationships for continuous expansion. The amount of data collected can be monitored in real time on the website's management platform. First, approximately 50 new nurses from the authors' unit were selected as the original deliverers of the survey. Subsequently, the colleagues or classmates of 'the original deliverers' were invited to participate in our online survey. A web page link to our questionnaire survey (https://www.wenjuan. com/) was sent by mobile phone to the participants during nurses' rest breaks. Moreover, the questionnaires were self-administered. Inclusion criteria: voluntary participation, having less than three service years and being registered nurses. Exclusion criteria: being irregular nurses, having more than three service years and refusing to participate in this work.

\section{Ethical considerations}

Individual consent was received from every participant nurse. To ensure anonymity, participants were informed of the anonymity and were asked to avoid using names of their colleagues or superiors during the interview. Written informed consent could not be received due to the anonymous survey approach. Hence, oral informed consent for the survey was approved by the Ethics Committee of the Harbin Medical University and was obtained from each new nurse. Once a questionnaire was completed, it was identified that the nurses had acquiescently agreed to participate in our survey.

\section{Instrument}

Workplace incivility

Workplace incivility was assessed using 12 items developed by Cortina $e t a l,{ }^{35}$ which were selected to represent workplace incivility on a 5-point Likert scale, ranging from 1 to 5 ( $1=$ never, $2=$ one time, $3=$ two and three times, $4=$ more than four times, $5=$ frequently). Higher scores represented a higher occurrence rate of workplace incivility. The Cronbach's alpha coefficient for this scale was 0.893 .

\section{Anxiety}

Anxiety was evaluated with one item: 'Does your job make you feel anxious?' This item was scored on a 5-point Likert scale ranging from 1 to 5 (1=never, $2=$ seldom, $3=$ occasionally, $4=$ often, 5 =frequently). According to past literature ${ }^{36}$ item measurement also had adequate reliability and validity.

\section{Resilience}

An instrument with a 4-item scale was used to measure the aspects of resilience suggested by Sinclair and Wallston, ${ }^{37}$ including one dimension. The participants in the study were asked to respond to their options ranging from 'never' to 'every day' on 5-point scale, and higher scores indicated higher resilience. The Cronbach's alpha coefficient for this scale was 0.797 .

\section{Job burn-out}

Job burn-out was measured using the Chinese version of the Maslach Burnout Inventory-General Survey, which has been widely applied across different occupational groups. ${ }^{38}$ The participants in this study were asked to respond using 7-point scaled response options from 0 (never) to 6 (frequently). The whole scale consists of three dimensions: emotional exhaustion (five items), cynicism (four items) and reduced personnel accomplishment (six items). The whole questionnaire consists of 15 
Table 1 Characteristics of the respondents $(n=696)$

\begin{tabular}{|c|c|c|c|c|}
\hline Characteristic & Classes & $\mathbf{N}$ & $\%$ & Mean \pm SD \\
\hline \multirow[t]{2}{*}{ Age } & $19-29$ & 672 & 96.55 & $24.55 \pm 2.10$ \\
\hline & $30-35$ & 24 & 3.45 & \\
\hline \multirow[t]{2}{*}{ Gender } & Male & 67 & 9.60 & - \\
\hline & Female & 629 & 90.40 & \\
\hline \multirow[t]{3}{*}{ Marital status } & Unmarried & 594 & 85.34 & - \\
\hline & Married & 99 & 14.22 & \\
\hline & Other & 3 & 0.44 & \\
\hline \multirow[t]{3}{*}{ Hospital level } & Tertiary hospitals & 580 & 83.30 & - \\
\hline & The secondary hospital & 90 & 12.90 & \\
\hline & First-level hospital & 26 & 3.70 & \\
\hline \multirow[t]{3}{*}{ Education level } & Secondary or below & 17 & 2.40 & - \\
\hline & Associate degree & 253 & 36.35 & \\
\hline & Bachelor or above & 426 & 61.20 & \\
\hline \multirow[t]{3}{*}{ Service years } & $0-1$ year & 357 & 51.29 & $1.71 \pm 0.81$ \\
\hline & $1-2$ years & 181 & 26.01 & \\
\hline & $2-3$ years & 158 & 22.70 & \\
\hline \multirow[t]{9}{*}{ Distribution department } & Rotation & 102 & 14.66 & - \\
\hline & Internal medicine & 165 & 23.70 & \\
\hline & Surgery & 178 & 25.57 & \\
\hline & Emergency & 3 & 0.44 & \\
\hline & Medical technology & 25 & 3.59 & \\
\hline & Outpatient service & 30 & 4.31 & \\
\hline & Gynaecology & 41 & 5.89 & \\
\hline & Paediatrics & 29 & 4.17 & \\
\hline & Others & 123 & 17.67 & \\
\hline
\end{tabular}

items. Higher scores indicated a significantly elevated degree of job burn-out. The Cronbach's alpha coefficient for his scales was 0.791 .

\section{Data analysis}

Descriptive statistical analysis was used to display the demographic variables and incidence rate of workplace incivility. Pearson's correlation coefficients were computed to examine the relationship between workplace incivility and other variables. We obtained the data through the questionnaires above. Meanwhile, the data were transferred from the network, and multivariate techniques also were adopted $(p<0.05)$; the difference was statistically significant. All analyses of the data were carried out using SPSS V.19.0 (IBM, BM SPSS Statistics for Windows).

\section{RESULTS}

\section{Descriptive results}

The demographic characteristics are shown in table 1 . The data indicate that a majority of the sample is women $(90.4 \%)$ with an average age of 24.6 years; almost $85.3 \%$ are unmarried. Among the participants surveyed, $83.3 \%$ are from the Tertiary hospitals and $61.2 \%$ had bachelor or above. Approximately, $51.3 \%$ of the participants' service years less than 1 year at their current hospital. The participants are primarily distributed into eight clinical departments.

The means, SD and Pearson's correlation coefficients of continuous variables are shown in table 2. As results exhibited, all variables were significantly correlated with each other. Workplace incivility was positively correlated with anxiety $(\mathrm{r}=0.371, \mathrm{p}<0.01)$ and job burn-out $(\mathrm{r}=0.238$, $\mathrm{p}<0.01)$. On the contrary, workplace incivility was negatively related to resilience $(\mathrm{r}=-0.191, \mathrm{p}<0.01)$. Compared with previous studies, ${ }^{39} 40$ the level of job burn-out of Chinese new nurses $(3.19 \pm 0.84)$ was significantly higher than that of British $(2.71 \pm 0.97)$ and Italian nurses $(2.31 \pm 0.88)$.

\section{Hierarchical linear regression models}

Several multiple linear hierarchical regression analyses were performed to examine the influence of workplace incivility on job burn-out, anxiety and resilience of new nurses (table 3). To examine this research, we conducted three mediation analyses using the methods based on 
Table 2 The means, SD, Pearson's correlation coefficient and reliability coefficient of variables

\begin{tabular}{|c|c|c|c|c|c|c|}
\hline Variables & $\mathbf{M}$ & SD & $\alpha$ & 1 & 2 & 3 \\
\hline Workplace incivility & 1.893 & 0.532 & 0.893 & & & \\
\hline Anxiety & 2.770 & 0.862 & - & $0.371^{*}$ & - & \\
\hline Job burn-out & 3.194 & 0.841 & 0.791 & $0.238^{*}$ & $0.436^{\star}$ & $-0.026^{*}$ \\
\hline
\end{tabular}

${ }^{*} \mathrm{P}<0.01$; Correlation is significant at the 0.01 level (two tailed).

$\alpha$, Cronbach's alpha; $M$, mean.

linear regression published by Baron and Kenny. ${ }^{41}$ Workplace incivility was posed as a dependent variable in this study, anxiety as a mediator variable and job burn-out as an independent variable. Besides, the resilience was seen as a moderating variable in these models. At the same time, to eliminate the effects of demographic variables around these regression models, age, gender, hospital level, working years and situation of education and department distribution were posed as control variables, as shown in table 3 .

The results showed that workplace incivility had a positive prediction function to generate anxiety $(\beta=0.364$, $\left.\mathrm{p}<0.01, \mathrm{M}_{2}\right)$ and job burn-out $\left(\beta=0.240, \mathrm{p}<0.01, \mathrm{M}_{5}\right)$ of new nurses. Hypotheses 1 and 3 were supported. Anxiety also had a positive influence on job burn-out $(\beta=0.405$, $\mathrm{p}<0.01, \mathrm{M}_{6}$ ), which confirmed hypothesis 2 . Further, the regression coefficient $\beta=0.093$ in model 6 decreased obviously compared with previous $\beta=0.240$ (in the model 5) after controlling for the mediation variable (anxiety), according to the method to test mediating effect proposed by Judd et $a l^{42}$ The mediating effect of anxiety and its significance were further tested by a Sobel test, referring to the inspection procedures developed by Preacher and Hayes. ${ }^{43}$ The mediation effect was calculated as follows: $\mathrm{ab}=0.564 \times 0.057=0.032, \mathrm{p}<0.01, \mathrm{z}=7.807$. Therefore, anxiety partly mediated the relationship between

Table 3 Hierarchical linear regression models of variables

\begin{tabular}{|c|c|c|c|c|c|c|c|c|}
\hline \multirow[b]{2}{*}{ Variables } & \multicolumn{2}{|l|}{ Anxiety } & \multicolumn{6}{|c|}{ Job burn-out } \\
\hline & $\mathbf{M}_{1}$ & $M_{2}$ & $M_{3}$ & $M_{4}$ & $M_{5}$ & $M_{6}$ & $M_{7}$ & $M_{8}$ \\
\hline \multicolumn{9}{|l|}{ Control variables } \\
\hline Gender & -0.085 & $-0.094^{\star \star}$ & 0.005 & 0.042 & -0.001 & 0.037 & 0.000 & -0.002 \\
\hline Hospital level & $-0.102^{\star \star}$ & 0.087 & -0.034 & 0.011 & -0.024 & 0.011 & -0.023 & -0.025 \\
\hline Education level & $0.107^{\star *}$ & 0.064 & 0.041 & -0.006 & 0.012 & -0.014 & 0.012 & 0.017 \\
\hline Department distribution & -0.004 & -0.006 & -0.011 & -0.01 & -0.013 & -0.011 & -0.014 & -0.014 \\
\hline \multicolumn{9}{|l|}{ Cause variable } \\
\hline Workplace incivility & & $0.364^{\star *}$ & & & $0.240^{\star \star}$ & $0.093^{\star \star}$ & $0.242^{\star *}$ & $0.724^{\star *}$ \\
\hline \multicolumn{9}{|l|}{ Mediating variable } \\
\hline Resilience & & & & & & & 0.020 & $0.400^{\star \star}$ \\
\hline Incivility resilience* & & & & & & & & $-0.564^{\star \star}$ \\
\hline $\mathrm{F}$ & $4.217^{\star \star}$ & $19.379^{\star *}$ & 1.543 & $24.535^{\star \star}$ & $7.367^{\star \star}$ & $22.426^{\star *}$ & $21.003^{\star \star}$ & $17.095^{\star \star}$ \\
\hline $\mathrm{R}^{2}$ & $0.035^{\star \star}$ & $0.165^{\star \star}$ & 0.013 & $0.200^{\star \star}$ & $0.070^{\star \star}$ & $0.207^{\star \star}$ & $0.057^{\star \star}$ & $0.069^{\star *}$ \\
\hline$\Delta \mathrm{R}^{2}$ & $0.027^{\star \star}$ & $0.156^{\star \star}$ & 0.005 & $0.192^{\star \star}$ & $0.060^{\star \star}$ & $0.198^{\star \star}$ & $0.054^{\star \star}$ & $0.065^{\star \star}$ \\
\hline
\end{tabular}

M1: explains the influence of demographic variables on anxiety.

M2: explains the influence of workplace incivility on anxiety.

M3: explains the influence of demographic variables on job burn-out.

M4: explains the influence of anxiety on job burn-out.

M5: explains the influence of workplace incivility on job burn-out.

M6: explains the influence of workplace incivility on job burn-out after bringing into the explanatory power of anxiety.

M7: explains the influence of workplace incivility on job burn-out after bringing into the explanatory power of resilience.

M8: explains the influence of workplace incivility on job burn-out after bringing into the explanatory power of resilience and

resilience Interaction.

${ }^{*} \mathrm{P}<0.05 ;{ }^{* *} \mathrm{P}<0.01$. 


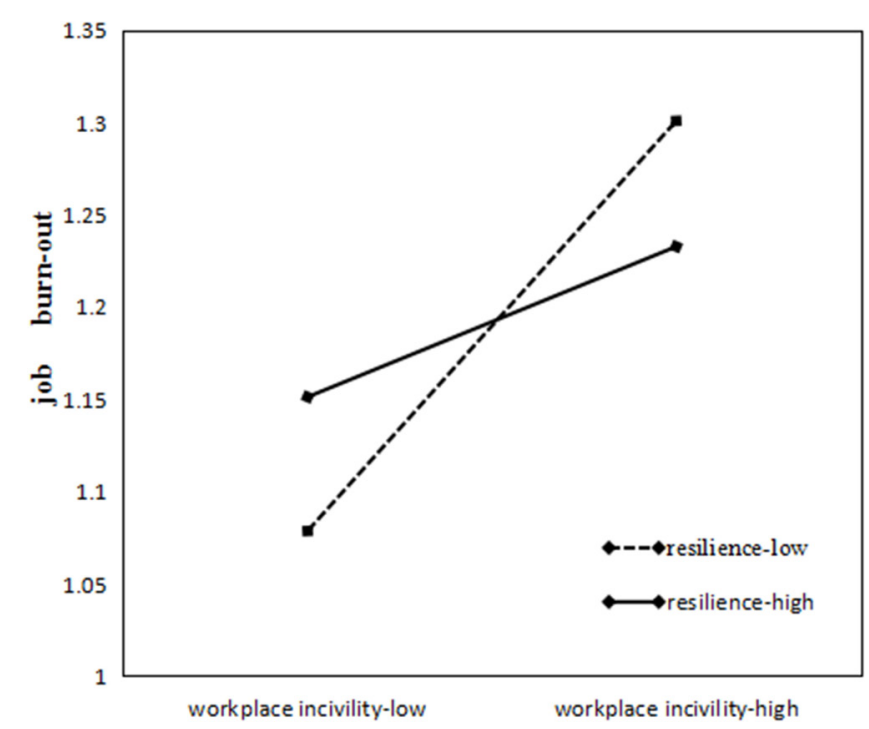

Figure 2 Effect of moderation.

workplace incivility and job burn-out of new nurses. Thus, hypothesis 4 was also confirmed. Moreover, the influence of the interaction between incivility and resilience on job burn-out was significant $\left(\beta=-0.564, \mathrm{p}<0.01, \mathrm{M}_{8}\right)$. The moderating effect was estimated by referencing a previous study. ${ }^{44}$ It showed that resilience moderated the relationship between incivility and job burn-out. Thus, hypothesis 5 was confirmed. This interaction effect is clearly illustrated in figure 2.

\section{DISCUSSION}

\section{The effect and mechanism on the new nurses' job burn-out} caused by workplace incivility

New nurses exposed to workplace incivility had a higher level of anxiety and job burn-out. This conclusion is consistent with previous research. ${ }^{13} 45$ Moreover, new evidence was also produced in this study that anxiety played a mediating role, and resilience had a moderating effect on the relationship between workplace incivility and job burn-out. That is, exposure to workplace incivility can result in increased degree of anxiety, which, in turn, can cause job burn-out. The new nurses with high levels of resilience can effectively buffer the negative effect caused by workplace incivility to a certain degree, which, in turn, can reduce the level of job burn-out. The possible mechanism is described below.

\section{The mediating role of anxiety in the relationship between workplace incivility and job burn-out}

In recent years, increased interest was paid to incivility in work settings. Although many previous studies on this topic focused on the adverse effects of uncivil behaviour, ${ }^{13}$ the studies on the mediators and moderators were insufficient. In this study, we attempted to investigate the subtle mechanism of incivility against new nurses. Clearly, workplace incivility is similar to language violence which, exists extensively. ${ }^{13}$ The new nurses are in need of various resources for career support, including material resources, human resources, mental resources and others. ${ }^{46}$ Generally speaking, workplace incivility is inevitable for new nurses as a part of work events launched from dissatisfied patients. In addition, because of lack of work experience and skills, new nurses are likely to encounter a series of disgruntled emotions from their superiors or colleagues-hence, the image called the 'kick cats effect'. ${ }^{47}$ The theoretical 'snowball effect' on incivility showed that it is inevitable to generate a ripple effect infected by some negative emotions in the workplace. ${ }^{48}$ Therefore, most new nurses are more likely to generate anxiety, restlessness, sense of injustice and helplessness. ${ }^{49}$ As time goes by, a state of physical and mental exhaustion and working weariness under stress from work and society will attack the new nurses. ${ }^{49}$ Job burn-out as a reflection of the chronic and interpersonal stress at the work setting, including emotional exhaustion, depersonalisation and ineffectiveness, can cause various manifestations such as depression, creativity failure, lower sense of personal worth, lower job satisfaction and so on..$^{51}$ Anxiety, as a basic human emotion, developed in the combat between human and environment and the process of survival adaptation. ${ }^{52}$ The affective events theory pointed out that employees can generate emotional reactions to what is going on, and these reactions influence their job performances and satisfaction..$^{53}$ Once the perception of anxiety appears, new nurses are likely to consume their own physical and mental energy for defence, followed by the sense of self-denial, inferiority and helplessness. The sense of low achievement and energy exhaustion and an emotional response to ineffectiveness effort could be highlighted, easily resulting in the increased risk of job burn-out. If employees cannot control and address the problems after the exposure to workplace incivility, anxiety ensues with negative emotions, for example, burn-out. Therefore, anxiety was defined as having a partial mediating role (shown in table 3 ) in the relationship between workplace incivility and job burn-out.

\section{The moderating effect of resilience in the relationship between workplace incivility and job burn-out}

The results of this study showed that, compared with new nurses with low levels of resilience, those with high levels of resilience were less affected by workplace incivility under the same working environment (table 3). A concept called the 'schema' in constructivism theory is an individual perception about the world and a way of thinking ${ }^{54}$ and a frame or an organisation structure of psychological activity. A schema is the starting point and the core of cognitive structure or the basis of human knowledge.$^{55}$ Therefore, the formation and transformation of schema is essential for the cognitive development of individuals. Cognitive development is affected by three processes: assimilation, hue and balance ${ }^{56}$ Resilience represents positive cognition, and individuals with high levels of resilience are more likely to recover from negative experiences and better adapt to the current environment. ${ }^{57}$ Resilience is also a necessary mental defensive ability when facing workplace incivility. From the theoretical kernel of edge angle, it is the positive selection and processing 
method under adversity. ${ }^{58}$ People with higher resilience can possess a positive attitude in the face of adversity. In this study, workplace incivility is seen as a working adversity for new nurses exposed to the unfriendly atmosphere. New nurses with higher levels of resilience could adjust their psychological cognition with positive emotions ${ }^{59}$ and thereby curb the consequence of incivility for physical and psychological harm and job burn-out slightly. For example, when their working ability is questioned, new staff with higher levels of resilience are more likely to try their best to improve and win the approval and respect of the patients or colleagues by their efforts without negative emotions. In addition, resilience presents the property of positive psychological traits. ${ }^{60}$ Fredrickson's expand-construction theory explains that the positive emotional experience reflects the individual's mental well-being and promotes the growth and development of the individual. ${ }^{61}$ Further, positive emotions have two core functions: first, instantaneous expansion function, which can expand instant thinking, and second, long-term function of construction, which can construct long-term physical, psychological, social resources and other resources. ${ }^{62}$ According to the two functions, new nurses with high levels of resilience are good at converting the pressure into motivating force; therefore, the negative emotions may be converted to positive emotions to reduce the loss of physical and mental energy of new nurses. Hence, new nurses with high levels of resilience can alleviate the negative impact of workplace incivility on job burn-out (shown in table 3). Consequently, resilience makes a positive adjustment by reducing the loss of mental health and decreasing the risk of job burn-out of new nurses. This study suggests that hospital managers should increase training to enhance the resilience of new nurses. The strategies used by nurses to build resilience mainly included cognitive reframing, emotional toughness, emotional connections and worklife balance, and compassionate behaviour. ${ }^{33}$ First, nursing managers should regularly provide communication skills and interpersonal adaptation training for new nurses and help new nurses to establish a correct cognitive of workplace incivility and improve their emotional toughness. Second, nursing administrators should encourage nurses to establish a work-family balance and expand their social networks. Third, nursing management should also increase organisational care such as timely discovery, adequate understanding and communication for new nurses who face workplace incivility.

\section{Limitations}

The survey collected data through an online questionnaire. The questionnaire contains many questions, and there may be reporting bias. This research adopted a snowball sampling method; thus, the regional data source ratio would have been unbalanced, and the data were restricted by regional results. Therefore, a rigorous sampling technique and a larger sample are needed in future research. This study is based on a cross-sectional design, which prevents determining the causal relationship between variables. We used several scales from abroad with cultural differences, requiring additional academic concern in a Chinese context. The data were collected from the self-reports of nurses from an online survey with less monitoring, which may have led to response bias due to social desirability or negative effect.

\section{Conclusion}

This study focused on workplace incivility in China's nursing field, using 'anxiety' and 'resilience' as a new interpretation path to analyse the mediating and moderating mechanism of the effects on new nurses' job burn-out caused by workplace incivility. First, this study verified that workplace incivility has a significant predictive function in job burn-out of new nurses in China's hospital setting. Second, anxiety played a partial mediating role in the relationship between workplace incivility and job burn-out. Finally, resilience played a moderating role in the relationship between workplace incivility and job burn-out. Workplace incivility in hospitals towards new nurses could increase their psychological anxiety ${ }^{63}$ and, in turn, gradually generate job burn-out. New nursing staff with high levels of resilience can effectively buffer the negative effects caused by workplace incivility, and the resilience can also repair psychological trauma to a certain degree after exposure to workplace incivility. The model theoretically extends the study of workplace incivility, especially to the Chinese new nursing group. This model suggests that nursing managers should pay attention to the growth and development of new nurses in the practice of nursing management, improving the resilience of new nurses and reducing their anxiety. This will help to reduce job burn-out of new nurses, thereby promoting the work efficiency and saving management cost. The study also provides a new theoretical contribution and practical guidance on maintaining physical and mental health of the Chinese new nurses. In turn, potential loss of nursing organisation can be prevented.

\section{Author affiliations}

${ }^{1}$ Department of Health Management, Public Health College of Harbin Medical University, Harbin, China

${ }^{2}$ Department of Human Resource Management, Fourth Affiliated Hospital of Harbin Medical University, Harbin, China

${ }^{3}$ Department of Pharmacy, Harbin Medical University Cancer Hospital, Harbin, China ${ }^{4}$ English teaching and research department, College of Humanities and Social Science, Harbin Medical University, Harbin, China

${ }^{5}$ Department of Outpatient Operating Room, First Affiliated Hospital of Harbin Medical University, Harbin, China

Acknowledgements The authors sincerely thank all participants who helped in collecting data and distributing questionnaires to the other subjects.

Contributors Conceived and designed the experiments: TS, YS and HG. Performed the experiments: ZS, SZ. Analysed the data: FX, JW and XD. Contributed reagents/ materials/analysis tools: TS, SZ and XD. Wrote the paper: YS, HG, ZS and LF.

Funding This study was funded by the Innovation Science Research Foundation of Harbin Medical University (No.2016RWZX09) to TS.

Competing interests None declared.

Patient consent Parental/guardian consent obtained.

Ethics approval Ethics committee approval was obtained from the Harbin Medical University Research Ethics Board. 
Provenance and peer review Not commissioned; externally peer reviewed.

Data sharing statement № additional data are available.

Open Access This is an Open Access article distributed in accordance with the Creative Commons Attribution Non Commercial (CC BY-NC 4.0) license, which permits others to distribute, remix, adapt, build upon this work non-commercially, and license their derivative works on different terms, provided the original work is properly cited and the use is non-commercial. See: http://creativecommons.org/ licenses/by-nc/4.0/

(c) Article author(s) (or their employer(s) unless otherwise stated in the text of the article) 2018. All rights reserved. No commercial use is permitted unless otherwise expressly granted.

\section{REFERENCES}

1. Katz D. The motivational basis of organizational behavior. Behav Sci 1964;9:131-46.

2. Robinson SL, Bennett RJ. A typology of deviant workplace behaviors: a multidimensional scaling study. Academy of Management Journal 1995;38:555-72.

3. Andersson LM, Pearson CM. Tit for Tat? The spiraling effect of incivility in the workplace. Academy of Management Review 1999;24:452-71.

4. Lauer CS. The end of civility? Gallantry may be passe, but good manners always make good sense. Modern Healthcare, 2002.

5. Pearson CM, Andersson LM, Porath CL. Workplace incivility, 2005.

6. Kirk BA, Schutte NS, Hine DW. The effect of an expressive-writing intervention for employees on emotional self-efficacy, emotional intelligence, affect, and workplace incivility. Journal of Applied Social Psychology 2011;41:179-95.

7. Saunders P, Huynh A, Goodman-Delahunty J. Defining workplace bullying behaviour professional lay definitions of workplace bullying. Int J Law Psychiatry 2007;30:340-54.

8. Pearson C, Porath C. The cost of bad behavior: how incivility is damaging your business and what to do about it: Penguin, 2009.

9. Penney LM, Spector PE. Job stress, incivility, and Counterproductive Work Behavior (CWB): the moderating role of negative affectivity. Journal of Organizational Behavior 2005;26:777-96.

10. Anderson LJ. Workplace incivility: extending research to the daylevel, 2013.

11. Blau G, Andersson L. Testing a measure of instigated workplace incivility. Journal of Occupational and Organizational Psychology 2005;78:595-614.

12. Hoel H, Sheehan MJ, Cooper CL, et al. Organisational effects of workplace bullying. Bullying and harassment in the workplace: Developments in theory, research, and practice, 2011:129-48.

13. Cortina LM, Magley VJ, Williams JH, et al. Incivility in the workplace: incidence and impact. J Occup Health Psychol 2001;6:64-80.

14. Skår R. The meaning of autonomy in nursing practice. J Clin Nurs 2010;19:2226-34.

15. Yun H, Jie S, Anli J. Nursing shortage in China: state, causes, and strategy. Nurs Outlook 2010;58:122-8.

16. Yip W, Hsiao WC. The Chinese health system at a crossroads. Health Aff 2008;27:460-8.

17. Bourbonnais R, Comeau M, Vézina M. Job strain and evolution of mental health among nurses. J Occup Health Psychol 1999;4:95-107

18. Han SJ, Bonn MA, Cho M. The relationship between customer incivility, restaurant frontline service employee burnout and turnover intention. International Journal of Hospitality Management 2016;52:97-106.

19. Maslach C, Schaufeli WB, Leiter MP. Job burnout. Annu Rev Psychol 2001;52:397-422.

20. Spence Laschinger HK, Leiter M, Day A, et al. Workplace empowerment, incivility, and burnout: impact on staff nurse recruitment and retention outcomes. J Nurs Manag 2009;17:302-11.

21. Aslam MS, Safdar U. The influence of job burnout on intention to stay in the organization: mediating role of affective commitment. International Journal of Management \& Innovation 2012.

22. Ronen S, Mikulincer M. Attachment orientations and job burnout: The mediating roles of team cohesion and organizational fairness. $J$ Soc Pers Relat 2009;26:549-67.

23. Lee K-J, Lee E. The relationship of emotional labor, empowerment, job burnout and turnover intention of clinical nurses. Korean Journal of Occupational Health Nursing 2011;20:130-42.

24. Harden RM. Stress, pressure and burnout in teachers: is the swan exhausted? Medical Teacher 1999;21:245-7.
25. Zellars KL, Perrewé PL. Affective personality and the content of emotional social support: coping in organizations. J Appl Psychol 2001;86:459-67.

26. Gabris GT, Ihrke DM. Does performance appraisal contribute to heightened levels of employee burnout? Public Personnel Management 2001;30:157-72.

27. Maslach C, Schaufeli WB, Leiter MP. JOB BURNOUT - annual review of psychology. 2003;52:397.

28. Zhou G, Yan X, Tang $X$, et al. The influence of emotion regulation on job burnout among teachers. Advances in Psychology 2012;2:93-8.

29. Lim S, Cortina LM, Magley VJ. Personal and workgroup incivility: impact on work and health outcomes. J Appl Psychol 2008;93:95.

30. Carter L, Loh J. What has emotional intelligence got to do with it: the moderating role of EI on the relationships between workplace incivility and mental health? International Journal of Work Organisation and Emotion 2017;8:41.

31. Spielberger CD, Gorsuch RL, Lushene RE. The state-trait anxiety inventory: John Wiley \& Sons, Inc, 2017.

32. Baumeister RF, Tice DM. Point-counterpoints: anxiety and social exclusion. J Soc Clin Psychol 1990;9:165-95.

33. Hart PL, Brannan JD, De Chesnay M. Resilience in nurses: an integrative review. J Nurs Manag 2014;22:720-34.

34. Hao S, Hong W, Xu H, et al. Relationship between resilience, stress and burnout among civil servants in Beijing, China: Mediating and moderating effect analysis. Pers Individ Dif 2015;83:65-71.

35. Cortina LM, Kabat-Farr D, Leskinen EA, et al. Selective incivility as modern discrimination in organizations. Journal of Management 2013;39:1579-605.

36. Abdel-Khalek AM. measuring happiness with a single-item scale. Soc Behav Pers 2006;34:139-50

37. Sinclair VG, Wallston KA. The development and psychometric evaluation of the Brief Resilient Coping Scale. Assessment 2004:11:94-101.

38. chaoping L, kan S, zhengxue L, et al. An investigation on job burnout of doctor and nurse. Chinese Journal of Clinical Psychology 2003;11:170-2.

39. Deery S, Walsh J, Guest D. Workplace aggression: the effects of harassment on job burnout and turnover intentions. Work, Employment and Society 2011;25:742-59.

40. Bobbio A, Bellan M, Manganelli AM. Empowering leadership, perceived organizational support, trust, and job burnout for nurses: a study in an Italian general hospital. Health Care Manage Rev 2012;37:77.

41. Baron RM, Kenny DA. The moderator-mediator variable distinction in social psychological research: conceptual, strategic, and statistical considerations. J Pers Soc Psychol 1986;51:1173-82.

42. Judd CM, Yzerbyt V, Muller D. Mediation and moderation, 2014

43. Preacher KJ, Hayes AF. Asymptotic and resampling strategies for assessing and comparing indirect effects in multiple mediator models. Behav Res Methods 2008;40:879-91.

44. Hayes AF. Introduction to mediation, moderation, and conditional process analysis: a regression-based approach. Journal of Educational Measurement 2013;51:335-7.

45. Chiaburu DS, Harrison DA. Do peers make the place? Conceptual synthesis and meta-analysis of coworker effects on perceptions, attitudes, OCBs, and performance. J Appl Psychol 2008;93:1082-103.

46. Simmons DC. Organizational culture, workplace incivility, and turnover: the impact of human resources practices. Dissertations \& Theses - Gradworks 2008;33:70-91.

47. LIUQUAN. Emotional pollution and cat kick effect. Psychology Express\&Psytopic 2007;1.

48. Estes B, Wang J. Integrative literature review: workplace incivility: impacts on individual and organizational performance. Human Resource Development Review 2008;7:218-40.

49. Porath CL, Pearson CM. Emotional and behavioral responses to workplace incivility and the impact of hierarchical status. Journal of Applied Social Psychology 2012;42:E326-E357.

50. Moore JE. Why is this happening? A causal attribution approach to work exhaustion consequences. Academy of Management Review 2000;25:335-49.

51. Kuokkanen L, Leino-Kilpi H, Katajisto J. Nurse empowerment, jobrelated satisfaction, and organizational commitment. J Nurs Care Qual 2003;18:184-92.

52. Tang HB. Summary of anxiety theories. Chinese Journal of Clinical Psychology 2009.

53. Weiss HM, Cropanzano R. Affective events theory: a theoretical discussion of the structure, causes and consequences of affective experiences at work. Research in Organizational Behavior 1996;3:1-74.

54. Fosnot CT, Constructivism. Theory, perspectives, and practice, 1996. 
55. Brandon AF, All AC. Constructivism theory analysis and application to curricula. Nurs Educ Perspect 2010;31:89-92.

56. Bryant PE. Cognitive development. British Medical Bulletin 1997;8:101-17.

57. Lazarus RS. From psychological stress to the emotions: a history of changing outlooks. Annu Rev Psychol 1993;44:1-22.

58. Reebs SP. Resilience. Natural History 2011;17:426-8.

59. Strohminger N, Lewis RL, Meyer DE. Divergent effects of different positive emotions on moral judgment. Cognition 2011;119:295-300.
60. Tugade MM, Fredrickson BL, Barrett LF. Psychological resilience and positive emotional granularity: examining the benefits of positive emotions on coping and health. $J$ Pers 2004;72:1161-1190.

61. Gao Z, Tong H. Role of positive emotions: the broaden-and-build theory. China J Health Psychology 2010;18:246-9.

62. Folkman S, Moskowitz JT. Stress, positive emotion, and coping. Current Directions in Psychological Science 2000;9:115-8.

63. Bartlett JE, li BME, Reio TG. Workplace incivility: worker and organizational antecedents and outcomes, 2008:8. 